in old age psychiatry and wish to consolidate their experience in preparation for ST5. The authors raise the issue of 'functionalisation' of general adult psychiatry and the risk that trainees may have very little exposure to in-patient treatment. That problem is resolved in the new proposals by two specific general adult placements each of 6 -months. The new proposals do not equitably consider training issues raised by functionalisation in old age psychiatry.

Old age psychiatry is a multifaceted subspecialty incorporating aspects of psychiatry, physical medicine and neurology. This marries well with the authors' suggestion of incorporating more of these two disciplines in psychiatric training. Offering an older adult placement as a CT2-4 may help to maintain the momentum of focus on these skills, and enhance the expertise of all trainees.

1 Oakley C, Jenkinson J, Oyebode F. Psychiatric training for the next generation. Psychiatrist 2013; 37: 25-9.

2 Tooke J. Aspiring to Excellence. Findings and Final Recommendations of the Independent Inquiry into Modernising Medical Careers. MMC Inquiry, 2008 (http://mmcinquiry.org.uk/Final_8_Jan_08_MMC_all.pdf).

Sabina Burza, Specialist Registrar, St Mary's Higher Training Scheme, Harrow Older People and Healthy Ageing Service, Bentley House Day Assessment Unit, Harrow, UK, email: sabinaburza@nhs.net; Claire Hilton, Consultant Psychiatrist, Harrow Older People and Healthy Ageing Service. doi: $10.1192 /$ pb.37.4.146a

Authors' response: We are encouraged that our paper has sparked some debate of these important issues. We agree with Conn \& Husain ${ }^{1}$ that conducting emergency assessments out of hours is a crucial component of training in psychiatry. We also support the Section of Neuropsychiatry's view that evaluation of the practical aspects of implementing a more integrated curriculum would be beneficial.

We understand the arguments put forward by Burza \& Hilton about the value of old age psychiatry and their assertion that it has non-parity with other specialties in our proposed scheme for postgraduate training in psychiatry. It was not our active intention to reduce trainees' exposure to old age psychiatry but this was a product of the challenge of trying to accommodate neurology, psychopharmacology and psychotherapy which currently are not routine placements. However, we intend our paper to stimulate discussion and would hope that this, and other perspectives, could lead to further shaping of a proposal for psychiatric training for the next generation.

1 Conn R, Husain M. Trainees want to work out of hours! Psychiatrist 2013 37: 117.

Clare Oakley, clinical research worker in forensic psychiatry, St Andrew's Healthcare, Northampton, and Institute of Psychiatry, King's College London, email: clare.oakley@kcl.ac.uk; Josie Jenkinson, clinical lecturer in old age psychiatry, Institute of Psychiatry, King's College London; Femi Oyebode, professor of psychiatry, University of Birmingham, consultant psychiatrist, National Centre for Mental Health, Birmingham.

doi: $10.1192 / \mathrm{pb} .37 .4 .147$

\section{A meeting point for neurology and psychiatry?}

Oakley et al highlight an important training gap in the current curricula of both psychiatrists and neurologists. Among other interesting considerations, the article proposes that 'in the first year of training, a 4-month placement in neurology becomes an integral part of core training [. . . ] to consolidate clinical examination skills and provide experience in the interface between neurological and psychiatric disorders'.

Historically, there is a tradition of cross-fertilisation between neurology and psychiatry, exemplified by the recent renaissance of the 'bridge' disciplines, neuropsychiatry and behavioural neurology. ${ }^{2-4}$ Standards of clinical practice and applied research have benefitted from specialists trained in the assessment and management of behavioural symptoms resulting from pathologies of the central nervous system. In some countries, including the USA and Germany, the opportunity of exploiting these reciprocal benefits is already formalised with integrated curricula at postgraduate training level. $^{2}$

In the UK, compared with their predecessors, psychiatry trainees have fewer opportunities to gain neurological and medical experience before specialisation. It has become increasingly difficult to move between specialties and there is little incentive for trainees to attain MRCP qualification. Over the past few years, the evolving discipline of neuropsychiatry has made some initial steps to bridge this gap. ${ }^{3,4}$

Based on these observations, the Royal College of Psychiatrists' Section of Neuropsychiatry agrees with the direction of the proposal by Oakley et al and encourages further discussion to translate valuable principles into practice. From the psychiatry trainee's perspective, achieving the College's core competencies (including working with patients with cognitive difficulties, neurodegenerative conditions) would be greatly facilitated by formal exposure to placements in neurology. The increasing necessity to optimise allocation and utilisation of healthcare resources would favour a revised curriculum, where the psychiatry trainee is provided with opportunities to learn about underlying neurological changes in traumatic brain injury, epilepsy or movement disorders. Trainees could also acquire the ability to diagnose conversion disorder based on physical signs (DSM-5).

Equally, care pathways which are currently far from efficient or cost-effective could be streamlined if the neurology trainee received exposure to the principles of conversion disorders and common behavioural symptoms and their management. $^{5}$

Finally, we feel that the same principles should apply to colleagues dealing with neurodevelopmental conditions, where formal training of child and adolescent psychiatrists would benefit from incorporating core elements of the paediatric neurologists' curriculum. In other countries (e.g. Australia, New Zealand) additional training in paediatrics and neurology is available through dual training programmes and additional certifications.

It is important that we examine psychiatric workforce development needs in the context of advances in neurosciences research and our developing knowledge of brain functions and brain disorders. The members of the Section of Neuropsychiatry express their wish that the proposal for a more integrated curriculum gains priority in the agenda of postgraduate educational committees, where the practical aspects of its implementation should be evaluated in the light of economical and logistical implications. 
Declaration of interest

Submission made on behalf of the Executive Committee of the Royal College of Psychiatrists' Section of Neuropsychiatry.

1 Oakley C, Jenkinson J, Oyebode F. Psychiatric training for the next generation. Psychiatrist 2013; 37: 25-9.

2 Silver JM. Behavioral neurology and neuropsychiatry is a subspecialty. J Neuropsychiatry Clin Neurosci 2006; 18: 146-8.

3 Agrawal N, Fleminger S, Ring H, Deb S. Neuropsychiatry in the UK: planning the service provision for the 21st century. Psychiatr Bull 2008; 32: $303-6$

4 Arambepola NMA, Rickards H, Cavanna AE. The evolving discipline and services of neuropsychiatry in the United Kingdom. Acta Neuropsychiatr 2012; 24: 191-8.

5 Earl J, Pop O, Jefferies K, Agrawal N. Impact of neuropsychiatry screening in neurological in-patients: comparison with routine clinical practice. Acta Neuropsychiatr 2011; 23: 297-301.

Rory Conn, CT3 Psychiatry, Camden and Islington NHS Foundation Trust, London, UK, email: rconn@doctors.org.uk; Andrea E. Cavanna, Consultant in Behavioural Neurology, Birmingham and Solihull Mental Health NHS Foundation Trust, UK, Honorary Reader in Neuropsychiatry, University of Birmingham, UK, and Visiting Professor in Neuropsychiatry, University of Pavia, Italy.

doi: $10.1192 / p b .37 .4 .147 a$

\section{Psychiatrists are not surgeons}

Reading the article by Archdall et al took us right back to our student days, where we both remember our emerging interest in psychiatry often being lambasted by those around us. Not so reassuring to see that some things never change.

What was most striking then, and it appears still now, are the beliefs that 'you can't cure anyone if you do psychiatry', 'you can't help people'. While we admit it has been a few years since either of us have worked in acute medicine or primary care, unless there have been some radical developments, we were not aware that conditions such as asthma, diabetes, arthritis or coronary artery disease could be easily cured either. Yet chronic physical illness is what the majority of medical students will end up managing in some form or another.

This research made us wonder whether we as psychiatrists paint a rather grave, dare it be said hopeless, picture of what our specialty involves when students spend time with us. Because surely the reality is that psychiatry has no lower a 'help' rate than other specialties that deal with both acute and chronic illness?

We did not go into medicine solely to cure people; we went into medicine to help ease suffering, in whatever small way that may be. And yes, that may be a listening ear instead of a scalpel or a pill, but no less is the satisfaction for us or relief for the patient.

So what is the answer to this? How do we help students see psychiatry for what it is, rather than this hopeless and helpless version that keeps being quoted back to us? We suggest addressing this stigma head on, acknowledging that we are seen as separate and different, and take students to see the good that we do.

1 Archdall C, Atapattu T, Anderson E. Qualitative study of medical students' experiences of a psychiatric attachment. Psychiatrist 2013; 37 $21-4$.
Eleanor J. Hogarth, ST4 in forensic psychiatry, email: Eleanor.Hogarth@ awp.nhs.uk, and Elizabeth O'Mahony, ST5 in forensic psychiatry, both at Fromeside, Blackberry Hill Hospital, Stapleton, Bristol, UK.

doi: $10.1192 / p b .37 .4 .148$

\section{Psychiatry tasters are needed early in foundation training}

As a core psychiatric trainee with an interest in recruitment whose decision to enter psychiatry was influenced by completing a Foundation Year 2 (FY2) post in the specialty, I read the article by Kelley et al ${ }^{1}$ with interest. The study showed a significant association between undertaking a Foundation Programme placement in psychiatry and entering core psychiatric training. One problem of the study, acknowledged by the authors, is that it did not look at the career preferences of the participants. As the authors admitted, it is likely that many of the doctors completing foundation placements in psychiatry already had a prior interest in it, and were therefore more likely to express a preference for, and be allocated to, programmes containing a rotation in psychiatry. Further research is therefore needed to evaluate further the influence of a foundation placement in psychiatry on eventual career choice, before we can infer that there is a causal link.

Given that the application process for core training begins in November, only those doctors completing an FY2 post in psychiatry within the first rotation of their FY2 year would experience psychiatry before applying for specialty training. This serves to highlight the potential value of tasters in allowing FY2 trainees to gain some experience in psychiatry before the application period.

Although I am in agreement that an increase in the number of foundation placements in psychiatry is important, I also believe that it is important to focus on attracting medical students to psychiatry at an earlier stage and ensuring that we do all we can to provide high-quality undergraduate training and placements in psychiatry, so that newly qualified doctors already have an interest in psychiatry before entering foundation training and have already thought about it seriously as a career choice.

1 Kelley TA, Brown J, Carney S. Foundation Programme psychiatry placement and doctors' decision to pursue a career in psychiatry. Psychiatrist 2013; 37: 30-2.

Thomas J. Burden, Core Trainee CT2, Cardiff and Vale University Health Board, Cardiff, UK, email: thomasburden@doctors.org.uk

doi: $10.1192 / p b .37 .4 .148$

\section{Influence of foundation job subspecialty}

I read with interest Kelley et al's article, ${ }^{1}$ particularly in light of previous correspondence in The Psychiatrist regarding whether some subspecialties are better with foundation doctors. I am a CT3 in psychiatry, with a hope to specialise in old age. During my foundation jobs I had a 4-month rotation working with general adult in-patients. I am perhaps not best placed to comment on the influence of which subspecialty of foundation job best influences recruitment to psychiatry as a whole, given that my decision to go into psychiatry was made even before entering medical school, however, I have been struck by the 